DOI: https://doi.org/10.24867/07DS04Lazarevic

\title{
RAZVOJ SISTEMA PODRŠKE OPERATIVNOM ODLUČIVANJU U LANCIMA SNABDEVANJA U VODNOM TRANSPORTU
}

\section{DEVELOPMENT OF DECISION SUPPORT SYSTEM FOR OPERATING PLANNING IN INLAND WATERWAY SUPPLY CHAINS}

\author{
Bojana Lazarević, Fakultet tehničkih nauka, Novi Sad
}

\begin{abstract}
Oblast - SAOBRAĆAJ
Kratak sadržaj - U okviru ovog rada izvršen je prikaz razvijanja korisničke aplikacije kao podrške operativnom odlučivanju u lancima snabdevanja u vodnom transportu. Takođe, prikazan je postupak implementacije aplikacije, zasnovanoj na osnovama upravljanja lancima snabdevanja, operativnog odlučivanja u vodnom stransportu $i$ sistemima podrške odlučivanju.
\end{abstract}

Ključne reči: Sistem podrške odlučivanju, lanci snabdevanja, aplikacija, sistem masovnog opsluživanja.

Abstract - This paper gives an overview of the developing desktop application for support system for operating decision in supply chains of water transport. Also, paper gives an overview of implementation of the application, which is based on supply chains management, inland waterway transportation, and decision support system.

Keywords: Decision support system, supply chain, application, queuing system.

\section{UVOD}

Današnje kompanije su fokusirane na razvoj logističke mreže kako bi ostvarile konkurentnost na tržištu pri čemu bi se na najbolji način zadovoljila potražnja kupca. To je doprinelo da se u poslednjoj deceniji promeni koncept proizvodnje sa jednostavnog proizvođača roba i usluga na proizvođače koji koordiniraju celim lancem snabdevanja [1]. Poslednjih godina broj teretnih vozila je sve veći čime se povećava zagušenje i dolazi do zagađenja životne sredine.

Zbog toga je veoma važno da se što više robe prevozi drugim vidovima transporta. Reke i kanali mogu da imaju veliku ulogu u novim obrascima održivog transporta. Jedno plovilo može da zameni 50 drumskih transportnih sredstava, što doprinosi smanjenju zagušenja kao i uštedi goriva. Vodni transport predstavlja pouzdanu alternativu u lancima snabdevanja.

Da bi se povećao trend korišćenja vodnog transporta potrebno je prvo definisati model lanca snabdevanja odnosno njegovu strukturu, poslovne procese i upravljačke komponente. Nakon toga potrebno je upravljati lancem snabdevanja na pravi način, što se postiže donošenjem odluka na različitim nivoima.

\footnotetext{
NAPOMENA:

Ovaj rad proistekao je iz master rada čiji mentor je bio dr Marinko Maslarić, vanr.prof.
}

$\mathrm{U}$ ovom radu stavljen je fokus na donošenje odluka na operativnom nivou, odnosno operativnom odlučivanju u vodnom transportu, konkretno u lučkoj logistici. U radu je opisano upravljanje lancima snabdevanja sa posebnim akcentom na upravljanje lancima snabdevanja u vodnom transportu, kao i opis faza i sistema za podršku pri odlučivanju. Osim toga opisana je tehnologija u kojoj je razvijena aplikacija za utvrđivanje najpovoljnijeg broja pristajališnih mesta kao jedan vid podrške odlučivanju.

Nakon opisa tehnologije, predstavljena je konkretna studija slučaja sa konkretnim primerima. kao i pravci budućeg poboljšanja i napredovanja aplikacije. Cilj rada je razvoj sistema za podršku operativnom odlučivanju u lancima snabdevanja u vodnom transportu na osnovu razvijene aplikacije za utvrđivanje najpovoljnijeg broja pristajališnih mesta.

\section{UPRAVLJANJE LANCIMA SNABDEVANJA}

\subsection{Osnovne napomene}

Lanac snabdevanja predstavlja skup organizacija koje obezbeđuju da se $\mathrm{u}$ jednom integrisanom procesu sirovine preprađuju u finalne proizvode $\mathrm{i}$ zatim isporučuju krajnjim korisnicima. Lanac snabdevanja čine svi fizički elementi i njihovi međusobni odnosi predstavljeni preko određenih funkcija i aktivnosti. Osnovni elementi lanca snabdevanja su snabdevači, proizvođači, distributeri i maloprodaje. Ovi elementi predstavljaju fiksni deo lanca snabdevanja odnosno osnovnu infrastrukturu lanca snabdevanja ili logističke mreže [2].

Koncept upravljanja lancima snabdevanja je usmeren ka tome da se sve aktivnosti u kompletnom lancu snabdevanja koordinisano upravljaju i realizuju u cilju sinhronizacije snabdevanja i potražnje na svim nivoima, da se razmenjuju i dele informacije i tehnologija u cilju povećanja inovativnosti i skraćenja ciklusa razvoja proizvoda, smanjenja vremena isporuke, zamene zaliha informacijama, smanjenja troškova, efikasnog i brzog odgovora na potražnju korisnika i povećanja nivoa usluge krajnjim potrošačima.

Objekat upravljanja lancima snabdevanja je sam lanac snabdevanja dok je ciljna grupa lanca snabdevanja krajnji korisnik. Cilj upravljanja lanca snabdevanja je da maksimizira krajnje stvorenu vrednost čime se povećava kompetititvnost celog lanca.

\subsection{Upravljanje lancima snabdevanja u vodnom transportu}

Svet bez transporta je svet bez trgovine, a samim tim i bez robe, pa je zbog toga nemoguće zamisliti normalno funkcionisanje bez transporta. Međutim, klimatske prome- 
ne, smanjenje prirodnih resursa kao i sve veći zastoji u saobraćaju dovode do toga da se moraju koristiti održivi vidovi transporta. Zbog toga je neophodno radikalno promeniti način na koji se prevozi roba.

Potražnja i propisi oblikuju lanac snabdevanja. Ključ za održivost ponude jeste deljenje i saradnja u lancu snabdevanja, tako da kompanije koje žele da smanje troškove dele skladišta, prevoz i informacije. Transport unutrašnjim plovnim putevima se izvršava u kombinaciji sa drugim vidovima transporta. Jedan od najvažnijih parametara za funkcionisanje intermodalnog transporta jeste lokacija dostavljača, kao i korisnika od koje zavise troškovi transporta, pretovara itd. Održivi transport bi se trebao planirati tako da se transport na dužim relacijama obavlja unutrašnjim plovnim putevima i železnicom, dok bi drumska vozila obavljala transport na kraćim relacijama. Pored toga potrebno je deliti transportna sredstva, informacije i skladišta kako bi se smanjila emisija štetnih gasova i transportni troškovi [5].

Istraživanja intermodalnog transporta u lancima snabdevanja se uglavnom fokusira na velike transportne udaljenosti, a ne na gradski prevoz. Logističke aktivnosti moraju biti prilagođene ograničenjima u korišćenju teretnog transporta u gradovima. Identifikovana su dva koncepta za povezivanje transporta unutrašnjim plovnim putevima sa gradskom distribucijom. Jedan od primera jeste isporuka u gradovima tako da se distribucija na poslednjem kilometru (engl. last mile delivery) izvodi npr. električnim čamcima u gradskim centrima gde se isporučuje veća količina robe kao što su pića, smrznuti proizvodi, građevinski materijal itd. Drugi primer jeste isporuka u ili iz gradova gde se roba prevozi do terminala u blizini ili centru grada pri čemu se isporuka na poslednjem kilometru realizuje drumskim transportnim sredstvima. U rešenjima gradske logistike za unutrašnju plovidbu u Evropi postoje rešenja koja uključuju nekoliko segmenata gradskog robnog transporta, za koje se može koristiti unutrašnja plovidba uključujući prevoz paletne robe, prevoz kontejnerske robe, isporuke do lokalnih prodavnica i restorana, dostava paketa, prevoz otpada i recikliranog materijala itd.

\section{ODLUČIVANJE U LANCIMA SNABDEVANJA}

\subsection{Faze i nivoi odlučivanja}

Odlučivanje u lancima snabdevanja zahteva potrebu za različitim metodologijama modeliranja, koje mogu pomoći u identifikaciji i implementaciji strategije za projektovanje lanaca snabdevanja visokih performasi. Neki od razloga složenosti donošenja odluka je veliki obim ponude, hijerarhijska struktura odluka, slučajnost različitih ulaza i dinamička interakcija među članovima $u$ lancu snabdevanja. Koristi od poboljšanih odluka su povećan protok, smanjenje zaliha, niži troškovi lanca snabdevanja, povećan povrat sredstava, veće zadovoljstvo kupaca.

Sve odluke vezane za upravljanjem lancem snabdevanja mogu se podeliti na strateške, taktičke i operativne. Strateško planiranje podrazumeva planiranje na duge staze u vremenskom periodu koji je duži od jedne godine. U ovoj fazi donose se odluke vezane za fizičku strukturu lanca snabdevanja, raspored troškova i prihoda i procesa koji će svaki element izvršavati. Ove odluke takođe odlučuju i izbor lokacije i dimenzionisanje proizvodnih i skladišnih kapaciteta, izbor i razvoj proizvoda koji će se proizvoditi ili skladištiti na različitim lokacijama, odabir vidova transporta koji će se koristiti za transport robe različitim pravcima $\mathrm{i}$ izbor vrste informacionog sistema koji će se koristiti. Odluke oblikovanja strukture lanca snabdevanja je veoma skupo jer se donose na duži vremenski period. Prema tome prilikom donošenja odluke ove vrste komapnije moraju uzeti $\mathrm{u}$ obzir neizvesnost $\mathrm{u}$ predviđanju tržišnih promena u narednih nekoliko godina. Taktičko planiranje uključuje kraći vremenski period do jedne godine. Struktura lanca snabdevanja je fiksna i ona predstavlja granicu u okviru koje se donose taktičke odluke. Kompanije započinju taktičko projektovanje sa predviđanjem zahteva tržišta za narednu godinu. Odluke na taktičkom nivou se izrađuju iz meseca u mesec, kao što su mesečne prognoze potražnje, planiranje transporta i distribucije, planiranje proizvodnje i planiranje potrebe za materijalima. Kod operativne faze odlučivanja vremenski okvir je najčešće orjentisan na period od jednog dana do nedelje [2].

Kod operativnog odlučivanja struktura lanca snabdevanja se smatra fiksnom a strategije planiranja su već definisane. Cilj funkcionisanja lanca snabdevanja je u uspostavljanju korektnog poslovnog $u$ odnosu na prihvaćeni nivo usluge korisnicima. Cilj ove faze odlučivanja je da se iskoristi prednost smanjenog nivoa neuzvesnosti kako bi se optimizovao krajnji učinak.Operativne odluke se odnose na određene aktivnosti u okviru neke organizacije i imaju skroman uticaj na budućnost. Operativne odluke se donose u okviru elemenata i uslova definisanih strateškim i taktičkim odlukama [2].

\subsection{Sistemi za podršku odlučivanju}

Sistem za podršku odlučivanju (engl. Decision Support System-DSS) je zapravo informacioni sistem koji podržava poslovne ili organizacione procese odlučivanja. Sistemi za podršku odlučivanju se koriste u menadžmentu, operacijama i planiranju u organizaciji (uglavnom srednji i viši menadžment) i pomažu ljudima da donose odluke o problemima koji se mogu brzo menjati i nisu određeni unapred - tj. nestrukturiranim i polustrukturiranim problemima odlučivanja. Sistemi za podršku odlučivanju mogu biti potpuno kompjuterizovani ili se mogu oslanjati na ljudsku snagu, a moguća je i kombinacija navedenih. Sistemi za podršku odlučivanju uključuju sisteme bazirane na znanju. Dobro dizajnirani sistem za podršku odlučivanju je interaktivni sistem baziran na softverima, namenjen da pomogne donosiocima odluka da skupe korisne informacije kombinovanjem sirovih podataka, dokumenata i ličnih znanja, ili poslovnih modela da bi identifikovali i rešili problem i doneli odluku [3].

Priroda i svrha ovog sistema jeste da utiču na širinu i sposobnost upravljačkog odlučivanja, unapređuju efikasnost i efektivnost procesa odlučivanja. Takođe pomaže pri otkrivanju, definisanju i rešavanju problema, olakšavaju interpersonalne komunikacije, ne zamenjuju menadžera $u$ donošenju odluka već pružaju podršku odlučivanju. Sistem podrške odlučivanju je struktuiran u nekoliko modula i pod-modula. Ovakva struktura omogućava lakše korišćenje sistema i maksimalnu fleksibilnost. 
Modularnost programa omogućava korisnicima da pristupaju samo oblastima za koje su zainteresovani. Takođe sistem može lako da se ažurira i da uključuje nove mogućnosti i informacije.

\section{RAZVOJ APLIKACIJE}

Optimalan broj pristajališnih mesta određuje se primenom metoda teorije verovatnoće i teorije masovnog opsluživanja. Osnovni kriterijum za obezbeđivanje optimalnog broja pristajališnih mesta jeste da se obezbedi obrada robe $\mathrm{u}$ zahtevanim količinima sa minimalnim troškovima. Da bi se obezbedila podrška odlučivanju pri izboru optimalnog broja pristajališnih mesta potrebno je izvršiti proračun najpovoljnijeg broja pristajališnih mesta. Da bi se izvršio takav proračun neophodno je utvrditi ulazne podatke za određivanje računskog broja pristajališnih mesta, ulazne podatke za određivanje eksploatacionih karakteristika pristajališta i ulazne podatke za određivanje troškova investicionih ulaganja i troškova eksploatacije. Aplikacija (Slika 1) se sastoji iz jednostavnog korisničkog interfejsa u kom korisnik unosi podatke na osnovu kojih dobija željene rezultate. U pozadinskom delu aplikacije nalaze se matematičke formule na osnovu kojih se vrši proračun svih potrebnih parametara.

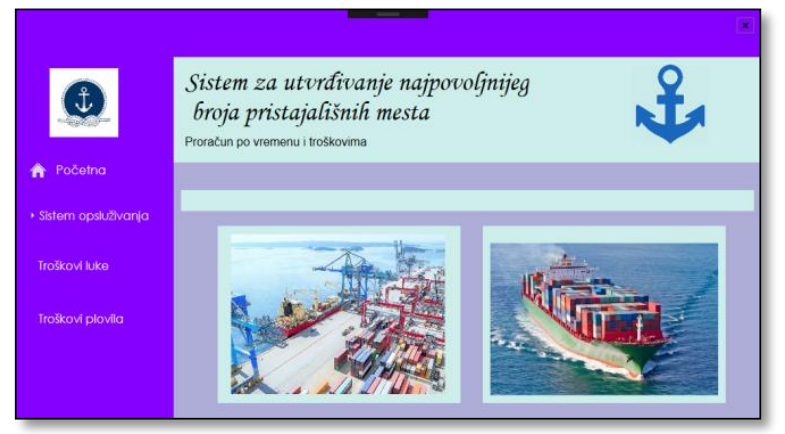

Slika 1. Početna strana korisničke aplikacije

Korisnička aplikacija se sastoji iz početne strane, dugmeta za izbor sistema opsluživanja na osnovu kojeg se računa najpovoljniji broj pristajališnih mesta za relativni prioritet i sistem masovnog opsluživanja (SMO) bez prioriteta. Nakon toga se nalazi opcija "Troškovi luke" na osnovu koje se računaju troškovi luke i poslednja opcija "Troškovi plovila" računa troškove plovila.

\subsection{Tehnologija za izradu aplikacije}

Aplikacija je razvijena u Visual Studio programskom okruženju, u C\# programskog jeziku korišćenjem WPF (Windows Presentation Foundation) tehnologije i MVVM (Model-View-ViewModel) dizajna. Microsoft Visual Studio [4] je proizvod Microsoft kompanije i predstavlja radno okruženje za razvoj softverskih aplikacija. Ovo okruženje korisnicima pruža mogućnost za kreiranje različitih tipova aplikacija kao što su desktop, web aplikacije, aplikacije za mobilni telefon i razne vrste servisa, što ga čini najkompletnijim integrisanim okruženjem današnjice. WPF predstavlja grafički podsistem koji je namenjen razvijanju aplikacija sa korisničkim interfejsom.

C\# je objektno-orijentisani program razvijen u kompaniji Microsoft i predstavlja jedan od najmlađih programskih jezika. Izumljen je sa ciljem maksimalnog iskorišćenja sposobnosti .NET Platforme i jedan je od programskih jezika koji je podržan u Visual Studio okruženju.

MVVM predstavlja arhitekturalni obrazac koji pruža mogućnost odvajanja prezentacijskog dela aplikacije poslovne logike, kao i njene implementacije [4].

\subsection{Opis aplikacije}

Jednokanalni sistem masovnog opsluživanja se deli na jednokanalni sistem masovnog opsluživanja bez prioriteta i jednokanalni sistem masovnog opsluživanja sa relativnim prioritetom kad neko plovilo ima prednost $\mathrm{u}$ odnosu na drugo. Kada korisnik klikne na dugme Sistem masovnog opsluživanja, sa desne strane će se pojaviti 2 kartice na osnovu kojih može da odabere da li želi da vrši proračun bez prioriteta ili sa relativnim prioritetom. Kada odabere neki od prioriteta, pojavljuje se tabela sa odgovarajućim parametrima, na osnovu kojih će se izvršiti proračun. (Slika 2). Parametri za proračun sistema masovnog opsluživanja sa relativnim prioritetom su isti kao i kod SMO bez prioriteta, s tim što se u ovom slučaju unosi i broj klasa prioriteta.

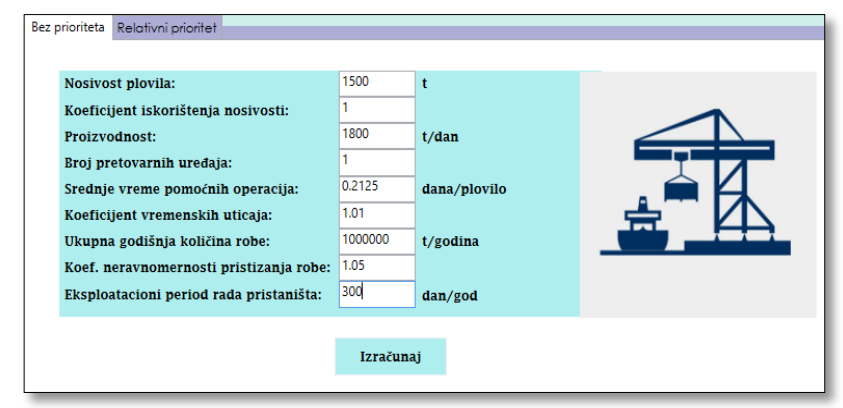

Slika 2. Parametri za proračun SMO bez prioriteta

$\mathrm{Na}$ osnovu unešenih parametara utvrđuje se opterećenje sistema, verovatnoća da je pristajalište slobodno/zauzeto, broj plovila na čekanju/obradi, vreme čekanja na obradu,i broj plovila u pristaništu. Svi ovi razultati zavise od toga da li je u pitanju jednokanalni ili višekanalni sistem masovnog opsluživanja kao i da li je u pitanju SMO sa relativnim prioritetom ili bez prioriteta.

Proračun troškova po varijantama broja pristajališta se vrši na osnovu proračuna troškova pristajališta i proračuna troškova plovila. Ukupni građevinsko eksploatacioni troškovi pristajališta se računaju na osnovu građevinsko - eksploatacionih troškova za vreme rada pristaništa i građevinsko - eksploatacionih troškova za vreme stajanja pristajališta (Slika 3).

Ukupni građevinsko - eksploatacioni troškovi plovila se računaju na osnovu građevinsko - eksploatacionih troškova plovila za vreme obrade u pristaništu i građevinsko - eksploatacionih troškova plovila za vreme stajanja pristajališta (Slika 4).

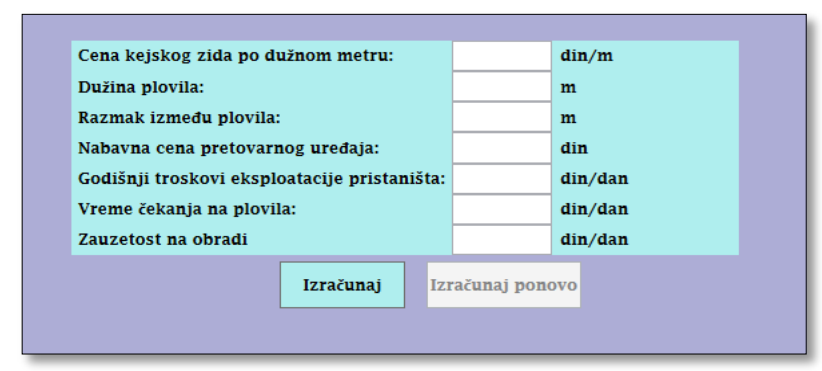

Slika 3. Parametri za proračun troškova luke 
Ukupni troškovi luke predstavljaju zbir troškova tokom rada luke i troškova za vreme stajanja, dok ukupni troškovi plovila predstavljaju zbir troškova plovila za vreme obrade u luci i troškova plovila za vreme stajanja.

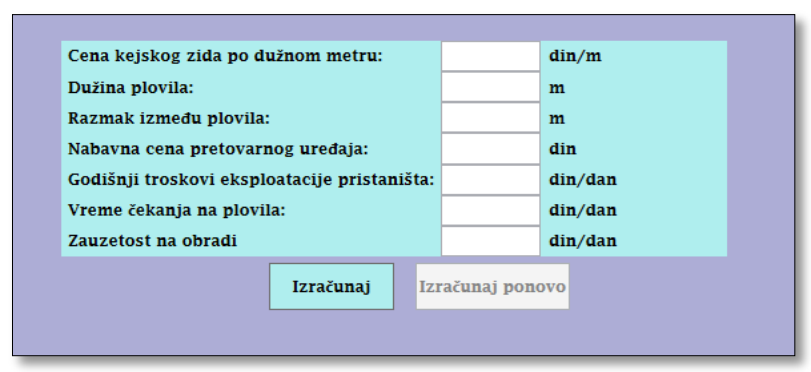

Slika 4. Parametri za proračun troškova plovila

\section{ZAKLJUČAK}

Na osnovu dobijenih proračuna dolazi se do zaključka da se sa povećanjem broja kanala za opsluživanje smanjuje opterećenje sistema, pri jednakom srednjem dnevnom intenzitetu pristizanja plovila. Samim tim verovatnoća da sva pristajališta budu slobodna se povećava pri većem broju kanala za opsluživanje.

Srednji broj plovila koja čekaju na obradu je znatno veći sa jednim kanalom za opsluživanje, dok se sa većim brojem kanala srednji broj plovila približava vrednosti 0 . Vreme čekanja na pretovar je takođe mnogo veće kada je situacija sa jednim kanalom za opsluživanje u odnosu na višekanalne sisteme. Srednji broj slobodnih pristališta se povećava pri većem broju kanala

Zahvaljujući aplikaciji operater u luci može na jednostavan način da dođe do rezultata na osnovu kojih može da planira i izvršava dalje operacije. Razvijanjem ovakvog sistema olakšava se sam rad operatera da na brz i efikasan način dođe do tačnih rezultata. Takođe, operater ne mora da poznaje formule niti da računa putem kalkulatora ili Excel-a. Pored izračunatih parametara sistema masovnog opsluživanja, aplikacija računa i troškove pristaništa i troškove plovila. Svi dobijeni rezultati imaju izlaz u Excel fajl, što operateru omogućava lakše manipulisanje podacima.
Pored navedenih opcija aplikacija ima mogućnost proširenja i unapređenja. Jedno od budućih proširenja bi bilo grafičko prikazivanje podataka putem raznih dijagrama i grafikona. Takođe, aplikacija bi mogla u budućnosti da poredi rezultate u nekom vremenskom periodu, što bi bilo od koristi za statističke analize.

\section{LITERATURA}

[1] Biswas T., Susmita S., A strategic decision support system for logistics and supply chain network design, Department of Computer Science and Engineering, St. Thomas' College of Engineering and Technology, Kolkata 700023, India

[2] Maslaric M., Osnove upravljanja lancima snabdevanja, Fakultet Tehničkih Nauka Novi Sad

[3] Michael G. Heffner Captain, A computer based decision support system (DSS) for developing logistic support analysis (LSA) requirements as part of the system engineering process, September 1989

[4] Guckenheimer, Sam, and Juan J. Perez. Software Engineering with Microsoft Visual Studio Team System (Microsoft. NET Development Series). Addison-Wesley Professional, 2006.

[5] Inland Navigation Water, Just Add Water

\section{Kratka biografija:}

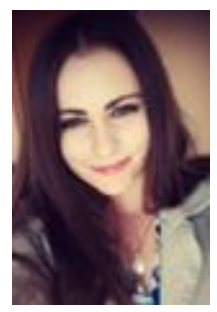

Bojana Lazarević rođena je u Milićima 1994. godine. Diplomirala je 2016. godine na Fakultetu tehničkih nauka u Novom Sadu na departmanu za Saobraćaj.

Kontakt: bojanalazarevic@ hotmail.com 